\title{
Pre-Cannulation Spasm during Transradial Access for Coronary Procedures: Can it be Prevented?
}

\author{
Dr. Babu Ezhumalai, MD, DM, FNB, FISE \\ Consultant Interventional Cardiologist, \\ Department of Interventional Cardiology, Fortis Escorts Heart Institute, \\ New Delhi, India
}

The success of transradial approach for coronary angiography and interventions depend on meticulously obtained radial artery access which in turn depends on palpating a good radial pulse. Unlike transfemoral approach wherein the access of femoral artery is rarely a problem, access and cannulation of radial artery has always been a nightmare for a subtle but significant group of operators opting for transradial approach for coronary angiography. ${ }^{1}$ Spasm of radial artery is the Achilles' heel of transradial coronary angiography and is usually encountered after cannulation of radial artery. ${ }^{2}$ Sometimes, this spasm can occur prior to cannulation as a result of repeated painful failed punctures of radial artery. ${ }^{3}$ This entity is called "pre-cannulation spasm". ${ }^{4}$ Once this occurs radial pulse will be lost, then transradial approach needs to be abandoned and switched over to transfemoral approach. Vasodilatation of radial artery on administering nitroglycerin through intravascular (both artery ${ }^{5}$ and vein $^{6}$ ) and topical ${ }^{7}$ routes has been well established. Of late, there is growing interest in administering various doses of nitroglycerin subcutaneously at the site of puncture for facilitating transradial access. ${ }^{3,8,9}$ Nitroglycerin does not depend on endothelium for its action and, when administered subcutaneously leads to smooth muscle relaxation and vasodilatation by releasing nitric oxide. Compared to many other muscular arteries, radial artery is more sensitive to nitroglycerin. In a recent study published, it has been objectively proven using ultrasonography that $500 \mathrm{mcg}$ of nitroglycerin infiltrated subcutaneously along with local anaesthesia significantly increases the diameter of radial artery. ${ }^{4}$ This vasodilation enhances the palpability of radial artery, prevents pre-cannulation spasm and enables the transradial puncture.

Therefore, unsuccessful punctures of radial artery can lead to pre-cannulation spasm of radial artery and this is prevented by administering nitroglycerin subcutaneously along with local anesthesia during transradial access. ${ }^{4}$ with experience, the dose of nitroglycerin practically selected for this purpose may be $100-200 \mathrm{mcg}$ and this can be routinely added to the local anaesthetic solution during transradial access.

\section{REFERENCES}

[1] Louvard Y, Lefevre T, Morice MC. Radial approach: what about the learning curve? Cathet Cardiovasc Diagn 1997; 42(4):467-68.

[2] Valsecchi O, Vassileva A, Musumeci G, et al. Failure of transradial approach during coronary interventions: Anatomic considerations. Catheter Cardiovasc Interv 2006; 67(6):870-78.

[3] Pancholy SB, Coppola J, Patel T. Subcutaneous administration of nitroglycerin to facilitate radial artery cannulation. Catheter Cardiovasc Interv 2006;68(3):389-91.

[4] Ezhumalai B, Satheesh S, Jayaraman B. Effects of subcutaneously infiltrated Nitroglycerin on Diameter, Palpability, Ease-of-puncture and Pre-cannulation Spasm of Radial Artery during Transradial Coronary Angiography. Indian Heart J. 2014; 66(6):593-7.

[5] Carrillo X, Fernandez-Nofrerias E, Ciompi F, et al. Changes in radial artery volume assessed using intravascular ultrasound: a comparison of two vasodilator regimens in transradial coronary interventions. J Invasive Cardiol 2011; 23(10):401-04.

[6] Zabeeda D, Medalion B, Jackobshvilli S, et al. Comparison of systemic vasodilators: Effects on flow in internal mammary and radial arteries. Ann Thorac Surg 2001; 71(1):138-41. 
[7] Boyle A. Radial Artery Dilation Study: The effect of topical administration of nitroglycerin and lidocaine versus lidocaine alone of the radial artery diameter. Available at: http://clinicaltrials.gov/ct2/show/study/NCT00686231. Accessed August 10, 2013.

[8] Ouadhour A, Sideris G, Smida W, et al. Usefulness of subcutaneous nitrate for radial access. Catheter Cardiovasc Interv 2008; 72(3):343-46.

[9] Candemir B, Kumbasar D, Turhan S, et al. Facilitation of radial artery cannulation by periradial subcutaneous administration of nitroglycerin. J Vasc Interv Radiol 2009; 20(9):1151-56. 